\title{
Comparing lithium-ion battery architecture performances with Colored Petri Net
}

\author{
Christophe Savard ${ }^{1}$ (D) $\cdot$ Laurent Pietrac ${ }^{2} \cdot$ Pascal Venet $^{2} \cdot$ Ali Sari $^{2} \cdot$ Eric Niel $^{2}$
}

Received: 12 July 2019 / Accepted: 19 November 2019 / Published online: 27 November 2019

(c) Springer Nature Switzerland AG 2019

\begin{abstract}
Conventionally, the basic cells constituting the multicellular energy storage systems are modeled by electrical schemes based on Thevenin's model. Other, more complex models incorporate the aging phenomena, resulting in a decrease in the State of Health of each cell. All these models remain analytical models and not discrete event systems. In this article, a discrete model is proposed, by detailing how each physical parameter is modeled. It is based on a no-timed Colored High-Level Petri Net. An example of a battery is simulated to validate this theoretical model. Its structure (number of cells) is declined under different architectures (connections between the cells) and is subjected to different resource dynamic allocation strategies. This Petri Net (PN) model makes easy, by adding a sub-network, to simulate different control laws and different resource management algorithms, whether or not allow commutations by forbiding all configurations that do not meet the specification or that will lead to accelerated cell aging. PN is used as a tool for comparing hardware architectures and cell control logic for a battery. Various conventional and innovative architecture are simulate. Different control laws can be compared in terms of performance, as lifespan and use of resources.
\end{abstract}

Keywords Battery · Battery aging · Electric power storage system · Discrete event system · Colored Petri Net

\begin{tabular}{|c|c|c|c|}
\hline \multicolumn{2}{|l|}{ List o } & $I_{\text {bat }}$ & Current deliver by the battery \\
\hline$T$ & Continuous time & $I_{n}$ & Cell nominal current \\
\hline Y & Dummy discrete time variable & $\theta_{a}$ & Ambient temperature \\
\hline$T_{\text {cycle }}$ & Cycle time (sum of charge, discharge and & SoC & Fundamental cell State-of-Charge \\
\hline & rest times) & $\mathrm{SoH}$ & Fundamental cell State-of-Health \\
\hline$i, j$ & Dummy variable for a row, a column & $D o D$ & Deep of Discharge $(D o D=1-S o C)$ \\
\hline$n, m$ & Number of rows, columns & $E S R$ & Cell Equivalent Series Resistance \\
\hline Cell $_{i j}$ & Cell in row i and column $\mathbf{j}$ & OCV & Cell Open-Current Voltage \\
\hline$I_{\text {cell }}, V_{\text {cell }}$ & $\begin{array}{l}\text { Cell current, voltage } \\
\text { Current, voltage in row i and column i }\end{array}$ & $R_{w}, C_{w}$ & $\begin{array}{l}\text { Cell First order Thevenin model } \\
\text { parameters }\end{array}$ \\
\hline$\theta_{i j}$ & Cell $_{i j}$ temperature & $Q$ & Cell instantaneous electrical charge \\
\hline $\begin{array}{l}S_{i j} A \ldots X \\
C b_{i}\end{array}$ & $\begin{array}{l}\text { Switch A...X in row } \mathrm{i} \text { and column } \mathrm{j} \\
\text { Balancing capacitor for row } \mathrm{i}\end{array}$ & $Q_{0}$ & $\begin{array}{l}\text { Cell maximum charge, aka operational } \\
\text { charge }\end{array}$ \\
\hline$S_{i j}+$ and $S_{i j}-$ & Balancing switches in row $\mathrm{i}$ and column $\mathrm{j}$ & $Q^{*}$ & Cell theoretical charge, aka cell capacity \\
\hline $\begin{array}{l}a \ldots y \\
l_{\text {applc }}\end{array}$ & $\begin{array}{l}\text { Element node a...y } \\
\text { Current specification }\end{array}$ & $L_{f}$ & $\begin{array}{l}\text { Cell announced lifetime, in number of } \\
\text { cycles }\end{array}$ \\
\hline
\end{tabular}

Christophe Savard, cjs@mainate.com, http://labs.mainate.com; Laurent Pietrac, http://www.ampere-lab.fr; Pascal Venet, http://www.ampere-lab.fr; Ali Sari, http://www.ampere-lab.fr; Eric Niel, http://www.ampere-lab.fr | ${ }^{1}$ Mainate.Labs, 16 rue Notre Dame de I'Oratoire, 43270 Allgre, France. ${ }^{2}$ Univ Lyon, Universite Claude Bernard Lyon 1, Ecole Centrale de Lyon, INSA Lyon, CNRS, Ampere, 69622 Villeurbanne, France. 


\begin{tabular}{|c|c|}
\hline$R U L$ & $\begin{array}{l}\text { Cell Remaining Usefull Life, in number of } \\
\text { cycles }\end{array}$ \\
\hline$A_{c}$ & DoD influence parameter for cell aging \\
\hline 4 & $\begin{array}{l}\text { Temperature influence parameter for cell } \\
\text { aging }\end{array}$ \\
\hline
\end{tabular}

\section{Introduction}

Accumulator batteries, often simply called batteries, are one of the topical technological issues to store electrical energy in a middle scale, that is to say for medium discharge time (several minutes to a day) [1]. A battery is an assembly of electrical energy storage cells and switches. Associate multiple cells in a battery allows it to deliver a higher voltage and current than a single cell. Indeed, cell values are often too low to meet industrial needs. The switches allow to define which cells are active and possibly allow to play on the cell intrinsic characteristics, as will be described below. These are driven by a Battery Management System (BMS) that applies different strategies to activate or isolate each cell. A BMS is an electronic card with a control part, often microprocessor-based, a data acquisition part specific to each cell and a cell control part with electronic switches. It is espacially in order to control the operational cells in any type of battery architecture that some switches are associated by a cell. The generic scheme of Fig. 1 presents a compilation of the different solutions present in the literature [2-4]. This element is associated in matrix form with a $n$ rows and $m$ columns structure battery, noted $(n, m)$. For a Cell $i_{i j}$, placed in the $i^{\text {th }}$ row and the $j^{\text {th }}$ column, switch $S_{i j} A$ is used to connect the cell in series on the same column with those in the upstream and downstream rows. The switches $S_{i j} A$ and $S_{i j} Z$ when they are respectively OFF and ON, allow to disconnect $C e l l_{i j}$ and replace it by a short circuit. The switches $S_{i j} B, S_{i j} C, S_{i j} D, \ldots$, $S_{i j} X$ make possible to distribute the upstream current flow from node $a$ to different cells of the downstream row by nodes $b$ to $x$ [5] or allow a parallel cell association. Finally, the switches $S_{i j}$ + and $S_{i j}$ - ensure the balancing function, which will be presented at point 4.1. In normal operation,

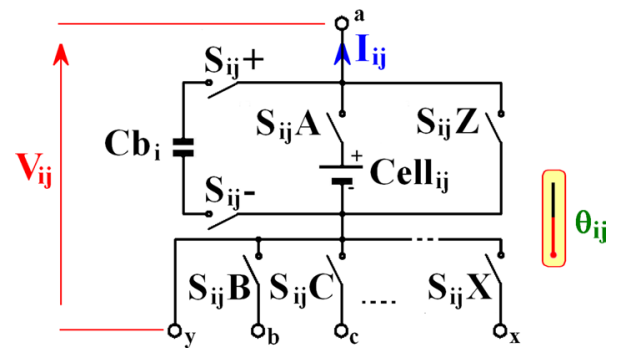

Fig. 1 An element: a cell with its switches these two switches are open. Temperature of each cell is noted $\theta_{i j}$. Usually, there are three major families deployed to built a battery: series-parallel architecture (SP), parallel-series (PS) and reconfigurable architecture. This latest requires the most switches [6].

Figure 2 shows how the $n * m$ elements are associated in matrix inside the battery. The BMS consists of two hardware parts: one for data collect from the sensors, the other for switches control. These two parts are supervised by a software part, realizing the synthesis of the orders. The BMS data acquisition part collects the measured data on each $C e l l_{i j}$ : voltage $V_{i j}$, current $l_{i j}$ and temperature $\theta_{i j}$. It ensures the cell protection, in particular by avoiding overloads and deep discharges. Depending on the setpoint, the current $I_{\text {applic }}$ demanded by the external application, it can act on the switches and activate or not each cell individually. $I_{\text {applic }}$ is the input instruction. If battery is equipped by switches $S_{i j} A$ to $S_{i j} X$, the BMS is also able to restructure the connections between the cells. Finally, battery deliver $I_{\text {bat }}$ current, conforms to $I_{\text {applic }}$. According to the cell data values and the $I_{\text {applic }}$ specification, the BMS control part calculates cell characteristic states reflecting their charge and their health largely related to aging phenomena and determines for each cell whether it should be active or not. On the other hand, a cycle is a period during which a fully charged cell is first discharged before being recharged. Adapted protocols are applied by the BMS to the cells in order to avoid any overload which could cause irreparable damage to the internal chemistry. They are generally made in two steps: first a charge under constant current, second under constant voltage (CC-CV charge protocols) [7]. In the rest of this paper, a complete recharge of a cell implies that it is done according to this protocol.

While many articles speak of continuous modeling or neural systems to represent the behavior of batteries, few resort to discrete systems by a PN. This article presents a discrete model describing the behavior of a single cell as well as a multi-cellular battery. Thereby in this study, the BMS supervision part is described by a Petri Net (PN). A PN is a more general model than an automaton for describing

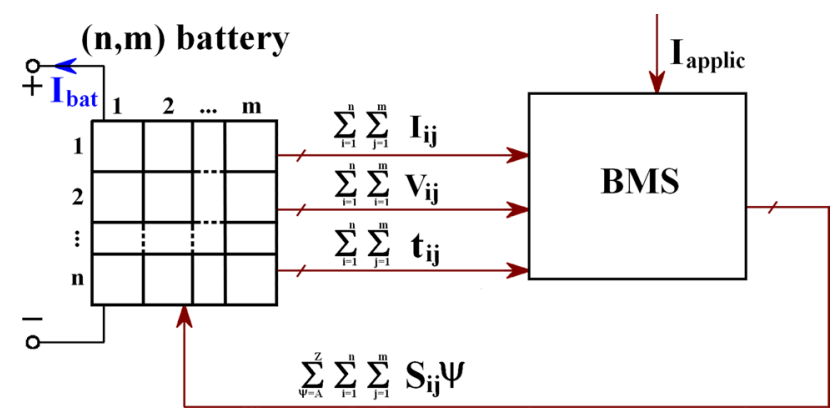

Fig. 2 Battery control architecture 
a discrete event system (DES). It is valid whatever the type of DES. In particular, it allows to model and control the behaviors of parallel, distributed, synchronized, communicating systems and sharing the same resources. The battery corresponds to this description since several paths of electric current circulate into the matrix through the cells distributed in rows and columns. Events (opening or closing switches) are synchronized and controlled by the supervisor. The supervisor forbids all configurations that do not meet the specification or that lead to accelerated cell aging. So, since it is a matter of controlling the opening and closing of switches, it is possible to resort to discrete modeling. That's why in [8], a PN model is used to model a photovoltaic panels association on a micro-grid, wind turbines and batteries. The states being associated with the source and battery states, so as to optimize the electrical flows on the network. Previously, PNs have already been used to model single-source system operation modes, depending on demand and energy stored amount in [9]. Among the different modeling possibilities, a PN associates formal semantics and visual representation with precise syntax and a graphical language. The operation of the system described by a PN is thus visualized by a synthetic structured and compact representation. Formally, a PN has properties such as liveliness, boundary, persistence, and re-initialization [10]. Dedicated mathematical tools ensure to test its properties. By including its BMS and switches, a battery can be considered as a DES. A discrete model to describe its operation can be established. The transitions correspond to switch commutations. Then, an algorithm can be implemented to control the cell matrix so as to modulate the energy stored in the battery.

The objectives of the application part of this paper are limited to compare three different battery architectures, regarding their performances on battery lifespan and to evaluate them. To do that, PN is presented and used as a tool for comparing hardware architectures and cell control logic. Depending on the state of the cells, the battery architecture and the needs of the external load, the BMS can activate or not all or part of the cells as their commandability is allowed by the switches. Whatever the battery architecture and structure, it is relevant to have an unique PN model of the battery that can be used to model its behavior. Likewise, a discrete model of each control law implantable in the BMS permits the study of their effects on the battery behavior. To compare the performances of each control law associated with each architecture, two performance parameters are used: the lifetime before failure and the remaining life potential in non-defective cells. After this analyse, we consider the command by determining whether to use an optimization algorithm for the cell activation improves performances or not. Literature presents many formal models describing a battery [11-13].
A discrete model by a Colored High Level Petri Network appears relevant to describe the cell functioning and their states since their sequential operation [14]. Furthermore, it can take into account aging phenomena. To date, the PNs have been used to model many sequential or random systems, but not to model the behavior of the cells, both in charge and in discharge. It is therefore in this work to achieve a discrete model that can be reused in the context of a programmable logic controller for running some cells and batteries.

In a first step, part 2 of this article is about presenting the continuous behavioral model of a cell and its equivalence in a discrete representation. Then, the following part shows how, from a cell PN model, a battery model can be built. After, Part 4 is devoted to the definition of different control laws, before presenting the simulations carried out in part 5.

\section{Examples of equations}

A cell has electrical characteristics such as its terminal voltage and the current flowing therethrough. Moreover, to describe the electric charge contained in the cell, two parameters are commonly used: the State of Charge $(\mathrm{SoC})$ and the State of Health $(\mathrm{SoH})$, respectively representing the amount of charge in the cell and the degree of wear. These parameters are related to the electric charge contained at the moment considered in the cell as well as its initial maximum electrical charge and its maximum electric charge at the moment considered. In addition, its temperature is a major parameter, particularly affecting its aging [15]. The behavior of the cell is modeled in the discrete event system in part 2.3, after explain it by a continuous electrical model and an aging model.

\subsection{Continuous models}

Continuous battery models are based on equivalent electrical circuits $[16,17]$. Some rely on internal electrochemical behavior [18]. They are mainly used to better understand the interactions between chemistry and battery performance. Others use neural circuits to refine adequacy between cell performance and internal phenomena [19-22]. The model presented in this article does not pretend to describe internal chemistry but to be use in a programmable logic controller. As a result, it simplify cell behavior. The number of cells inside a battery is function of power and energy that the battery must deliver. Conventionally, a source of electrical energy is represented by a first-order Thevenin generator model, in generator mode convention, as represented in Fig. 3a. The model considers the internal equivalent series resistance $(E S R)$. The 
(a) First order

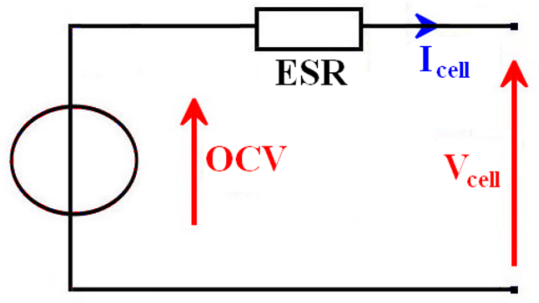

(b) Second order



Fig. 3 Thevenin electrical equivalent models for a cell

currently market-leading technology for batteries is the lithium-ion because of its good features in energy density and longevity. Indeed, for a cell, the open-circuit voltage $(O C V)$ is different according to the electrode nature. A cell provides a current $I_{\text {cell }}$ with a voltage $V_{\text {cell }}$. However, this model is too simplified to accurately reflect the cell electrical behavior. The second-order model adds to the series resistor and the ideal voltage generator a parallel association of a resistance $R_{W}$ and a capacitance $C_{W}$, so as to take the relaxation phenomena into account [23]. Indeed, $O C V$ is not directly measurable on cell terminals before a time corresponding to the return to thermodynamic equilibrium [24]. These components, shown in Fig. 3b, corresponding for $C_{W}$ to the double-layer capacitance between the electrodes and the electrolyte and for $R_{W}$ to a resistance related to the charge transfer between them.

The SoC parameter represents the electric charge that a cell contains at a time $T$ with respect to the maximum electric charge that it can contain at this time $T$, as depict by Eq. (1), when $Q(T)$ is the instantaneous charge at time $T$ and $Q_{0}(T)$ is the maximum electric charge or the operational charge at same time.

$\operatorname{SoC}(T)=\frac{Q(T)}{Q_{o}(T)}$,

Other more complex models exist [25], based on the cell internal chemistry, sometimes dissociating ESR in two, according to the $I_{\text {cell }}$ current direction. By convention, in generator mode, the $I_{\text {cell }}$ current is rated positive when the cell operates in discharge mode. It is negative when cell operates in charge mode. However, these models require higher computation times [26] and provide a SoC estimation precision which is often not necessary. Moreover, they present a static nature, not reflecting the aging phenomena. The cell aging is measurable by its $\mathrm{SoH}$ which represents the amount of electrical charge that a cell is able to store at a time $T$ with respect to its initial maximum electrical charge $Q^{*}$ as shown in the Eq. (2). $Q^{*}$ is the cell theoretical electrical charge, also call capacity. As they are reports of the same quantities, SoC and SoH varies from 0 to 1 .

$\operatorname{SoH}(T)=\frac{Q_{0}(T)}{Q^{*}}$,

To describe the continuous but non-linear relationship that exists between the open-circuit voltage and the state of charge, the formal Nernst's model [27] uses Eq. (3). The three Nernst's parameters $k_{j}$ for $j$ ranging from 1 to 3 can be determined experimentally [28].

$\mathrm{OCV}(\mathrm{SoC})=k_{1}+k_{2} \cdot \ln (\mathrm{SoC})+k_{3} \cdot \ln (1-\mathrm{SoC})$,

\subsection{Aging continuous models}

The lithium-ion cell aging is carried out in two different ways: in a calendar manner and in a cyclic manner [29]. In both cases, it results in an operational charge $Q_{0}$ decrease and in a series resistance ESR increase. Aging mechanisms are mainly related to the materials used to make the electrodes, the electrolyte composition and the operating conditions. Aging is thus accentuated by the following parameters:

- the operating anf the storage temperature of the cell;

- the current flowing in the cell;

- the charge variation during a cycle (discharge then recharge).

This last point introduces the notion of Deep of Discharge (DoD) which translates the difference between the SoC at the end of a cycle (SoC $\left.C_{\text {end_of_cycle }}\right)$ and the $\mathrm{SoC}$ at the beginning, which is equal to 1 if cell is fully recharged before. $\mathrm{DoD}$ is the to-one complement of the $\mathrm{SoC}$, as indicated by the Eq. (4).

$\operatorname{DoD}(T)=1-\operatorname{SoC}(T)$,

Other conditions of use can impact the aging rate such as the cycle frequency or the accumulation of energy extracted cycle by cycle [30]. These complementary points are not be modeled here because they only have an influence at the margin with respect to the influence of temperature, current and DoD.

Realization conditions also impact the way a cell ages [31]. To heed this point, a variability will be introduced in 


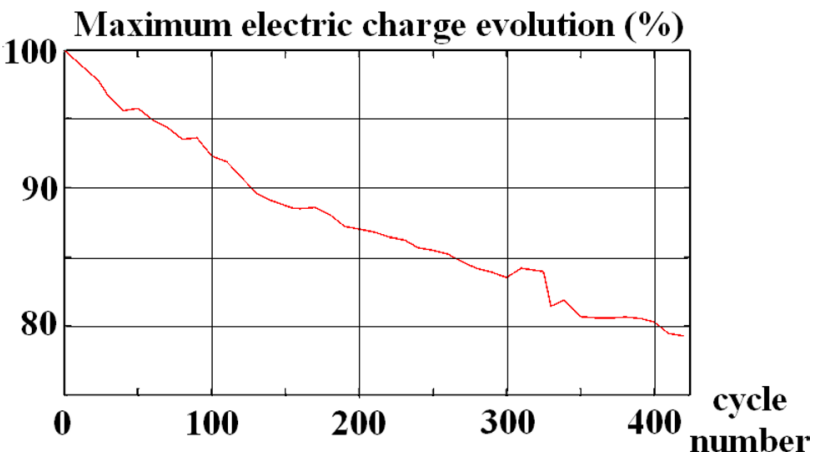

Fig. $4 \mathrm{LifePO}_{4}$ cell operational capacity loss by cycling [32]

the cell intrinsic values associated in the simulated batteries: on the initial ESR (which will grow as they age) and on the capacity (which will decrease as aging). At the end, the aging is measurable by monitoring $\mathrm{SoH}$ or $Q_{0}$ as performed on a lithium-ion cell $\left(\mathrm{LiFePo}_{4}\right)$ example with a $60 \mathrm{Ah}$ capacity, fully discharged in each cycle, under a $50^{\circ} \mathrm{C}$ temperature, corresponding to an operating temperature in a closed box, given in Fig. 4 [32]. This example demonstrate that its lifespan is equal to 400 cycles if it is specified that the cell have to be able to store at least $80 \%$ of its $Q^{*}$.

Current influence is mainly felt for high currents, higher than the nominal current [33]. The nominal current is worth in literal (in Ampere) the cell capacity value (expressed in Ampere-hour). That is, for example a nominal current $I_{n}$ equaling $1.2 A$ for a cell having a $1200 \mathrm{mAh}$ capacity. The simulations will be performed considering that the battery is not requested beyond its rated current $I_{n}$. This means the current is nearly always lower than the nominal current, which means that only two parameters are to be considered for the cell aggravating aging rate: the temperature, which influence will be represented by a parameter $A_{t}$ and the DoD, modeled by a parameter $A_{d}$. The respective influence shapes are given in Fig. $5 \mathrm{a}$ for DoD influence and Fig. $5 b$ for temperature.

The $\rho$ parameter represents the DoD influence in aging. Typically, it is between -1 and 0 [34]. The $A_{d}$ parameter evolves according to Eq. (5).

$A_{d}=(1-D o D)^{\rho}=S o C_{\text {end_of_cycle' }}^{\rho}$

The Arrhenius law allows to describe the temperature influence in cells. The typical values for the cell activation energy $E_{A}$ is between 0.4 and $1 \mathrm{eV} \mathrm{[35].} \mathrm{The} \mathrm{ambient} \mathrm{tem-}$ perature $\theta_{a}$ is considered here at $25^{\circ} \mathrm{C}$. The $A_{t}$ parameter evolves according to Eq. (6) with $K$ as Boltzmann constant $\left(K=8,617.10^{-5} \mathrm{eV} / K\right)$.

$A_{t}=e^{\frac{E_{A}}{K}\left(\frac{1}{273+\theta a}-\frac{1}{273+\theta}\right)}$, (a) DoD influences on aging

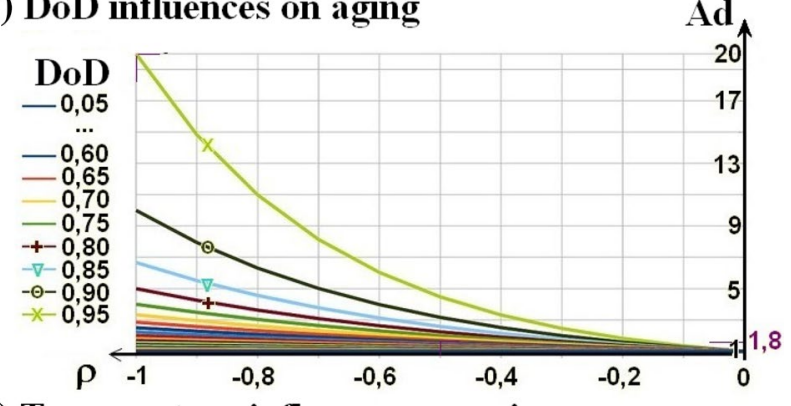

(b) Temperature influences on aging

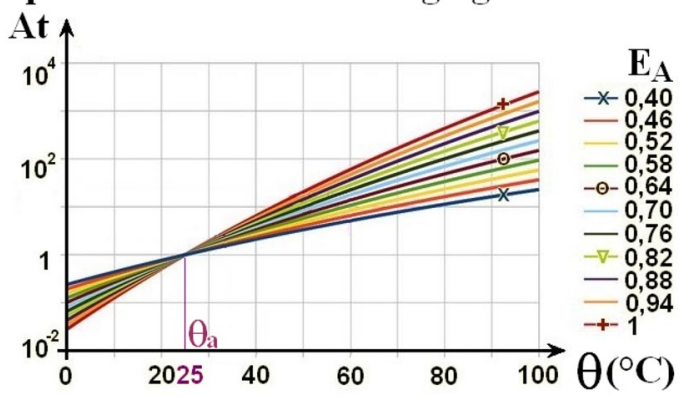

Fig. $5 \mathrm{LifePO}_{4}$ cell operational capacity loss by cycling [32]

Thus, when a cell is subjected to continuous cycling, regularly charged and discharged from the same electrical charge, its SoH decreases over cycling. Equation (7) describes the SoH decreasing as a function of cycle number, counted by the dummy variable $Y$, where $L_{f}$ is the announced lifespan (in cycles), given by the cell manufacturer for a normal use. $\mathrm{SOH}_{\text {lim }}$ is the minimum value of the $\mathrm{SoH}$ from which the cell is considered to be too old, which results in an inability to store more than $\mathrm{SOH}_{\text {lim }}$ times the capacity $Q^{*}$. Commonly $\mathrm{SOH}_{\text {lim }}$ is worth 0.8 , especially for electric and hybrid vehicle applications [36].

$\operatorname{SoH}(Y)=\operatorname{SoH}(Y=0)-\left(1-\mathrm{SOH}_{\lim }\right) \cdot \sum_{k=1}^{Y}\left[\frac{A_{d}^{(k)} \cdot A_{t}^{(k)}}{L_{f}}\right]$,

To define the aging of a cell, it is also possible to use the notion of remaining usefull lifetime (RUL). Indeed, if the $\mathrm{RUL}$ is expressed in number of cycles made at temperature and DOD defined by the manufacturer, it will decrease by one unit at each cycle. When the $\mathrm{SoH}$ has reached $\mathrm{SOH}_{\text {lim }}$ it is considered for simplification that the ESR has doubled according to the same variation law as the $\mathrm{SoH}$.

\subsection{Cell PN model}

To carry out the cell discrete model, the CPN-Tools software was use. This open-source tool allows to edit, simulate and analyze colored PNs. The software includes a 


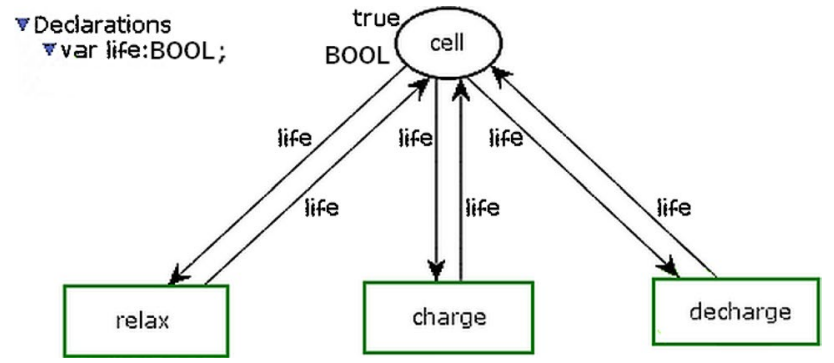

Fig. 6 Cell PN model

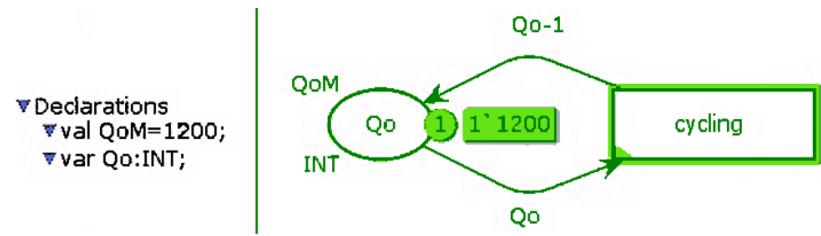

Fig. 7 PN modeling operational charge in a cell

graphical representation and a command panel, allowing to describe the colors, variables and functions used in the graphical interface. The functions are implanted in the transition guards or to weight the arcs. To represent a cell by a discrete model, the variables describing the cell state and operation: SoC, $Q(T)$, SoH should be taken as PN states. A cell can be in three different states, depending on the current value flowing through it: charging, relaxation or discharging modes. So, a cell PN model is describe by Fig. 6 . The cell is either functional or not. This is represented by a life boolean token. Depending on the state of the battery (《relax $\gg, \ll$ charge $\gg, \ll$ deharge $\gg$ ) the corresponding transition is fired. The token life goes through the transition to return to the $\ll c e l \gg$ state. Instead of being returned as it is, it can be modified by adding a function on the return arc of each transition. The cell can run in a relax mode, if its current $I_{\text {cell }}$ is equal to zero, in charging mode if its current is negative (energy is supplied to the battery) or in discharge mode (write here as $\ll$ decharge $\gg$ ) if its current is positive.

As a cell discharges, its $\mathrm{SoC}$ decreases concomitantly. So, expressing the SoC or $Q_{0}$ is the same. To model the $Q_{0}(T)$, an integer color (INT) token is used. For that, a PN contains a $\ll Q o \gg$ state. Its color rank from 0 to QoM, an initial value. For example, QoM set here at 1200 for a $Q_{0}=1200 \mathrm{mAh}$ cell. In this net, only one $\ll$ cycling $\gg$ transition is sufficient. At each end of cycle, the transition is fired. At first, it is considered a decrease of one unit on the operational charge at each cycle. Also, the Fig. 7 PN models its decay. In the Fig. 6 scheme, it is necessary to add a $\ll$ cycling $\gg$ transition. The token contained in the $\ll$ cell $\gg$ state must thus comprise several color fields: a

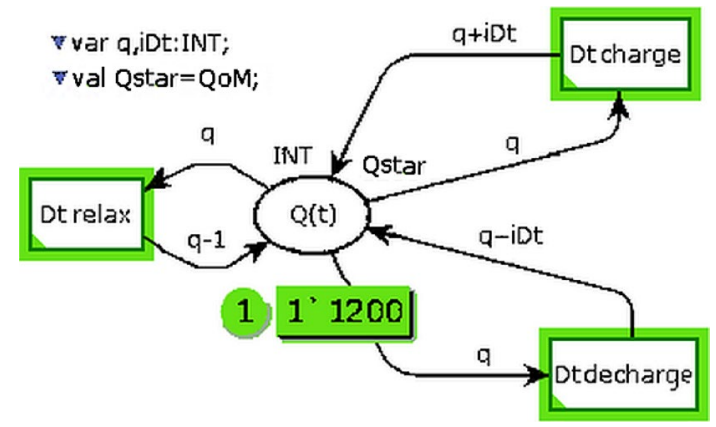

Fig. 8 PN modeling instantaneous charge in a cell

(a) Ad Ad parameter linearization



(b) At At parameter linearization

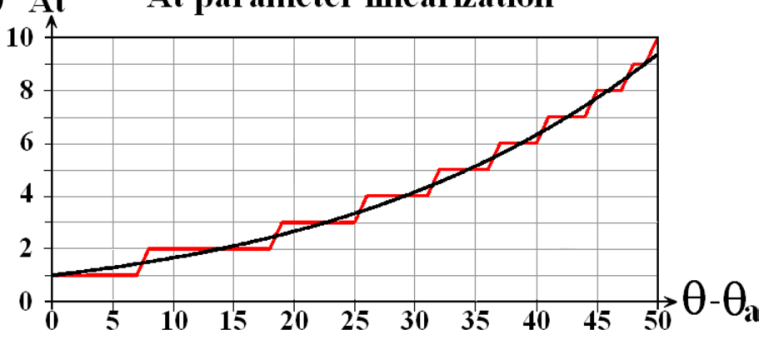

Fig. 9 Aging parameters digitization process

boolean color field for the \#life data and an integer for the \#Qo data field.

Another field of the multicolor token must represent the instantaneous electric charge $Q(T)$. Figure 8 depicts the instantaneous charge calculation. It is modeling in the $\ll Q t \gg$ state. At each transition firing, the charge contained in integer field $\ll Q(t) \gg$ token varies by an $i D t$ value. Qstar is the initial value, equal to $Q o M$. In the relaxation phase, it is decremented to simulate self-discharge.

Then, knowing $Q_{0}$ and $Q(t)$, it is possible to determine the SoC by using Eq. (1). In order to model the aging parameters $A_{d}$ and $A_{t}$ by integer numerical values, linearization can be carried out by part, as shown by Fig. 9 . The black curves represent the parameter evolution respectively according to the DoD and the temperature $\theta$ beyond the ambient temperature $\theta_{a}$, from Fig. 9. Thus $A_{d}$ varies from 1 to 3 according to the energy extracted in the cell during a cycle and $A_{t}$ between 1 to 10 depending 
on the cell temperature. These relations between $A_{d}$ and the DoD, as well as between $A_{t}$ and temperature, can be described by a linearized by-part function named here $\ll \operatorname{det} A d \gg$ and $\ll \operatorname{ded} A t \gg$ respectively. To calculate the DoD, two more fields must be added to the multicolored token: the maximum value of the instantaneous charge at the beginning of a cycle before discharge and the minimum value reached during the cycle, noted here $Q \max$ and Qmin. Temperature evolution is current related [37] and integrate an equilibrium return when cell is in rest. The linear relations between the temperature evolution, related to the current value, diminished of a return to thermodynamic equilibrium at the ambient temperature are then the object of functions allowing to calculate it from the current. Current have to be specified in another field of the token $i$.

Consequently, Fig. 10 presents the $A_{t}$ and $A_{d}$ parameter evolution model in function of temperature and DoD. The function modeling the second aging parameter variations is on the same shape. Fields $\ll A d \gg, \ll A t \gg$, and $\ll t \gg$ (for temperature) must be added in the multicolor token.

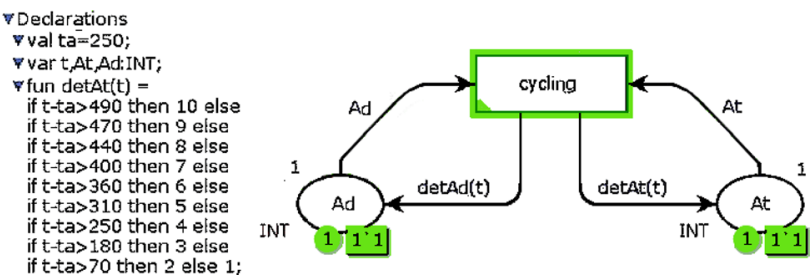

Fig. 10 PN modeling $A_{t}$ parameter
In the formulas and tokens of the PN, the temperature $\theta$ is designated by the variable $t$, to lighten the writing.

Thermal simulation is important for determining the storage system performance $[38,39]$. There are various models that have been published for the SSEEs [40-46]. For the present study, the model is limit to a simple growth and decrease of the cell temperature according to the electrical intensity crossing a cell $[37,47]$. In the same way, since this study must mainly validate the use of a PN in order to describe a cell functioning, the heat transfer phenomena between cells $[48,49]$ which take place in the heart of a battery are not taking into account. Then, at each end of cycle, the RUL, represented by a $\ll$ Rest $\gg$ field, must be reduced. In the same way, two other fields must be created to describe the evolution of the ESR and the OCV, as indicated previously: the fields $\ll R s \gg$ and $\ll V \gg$.

The cell PN model can be obtained by aggregating all the previous points. The Fig. 11 presents this model in which the «cycle $\gg$ state counts the cycle number undergone by the cell. It is externalized because it is the result of the cell intrinsic factors combined to the cycling. The three $\ll$ cyclrlx $\gg, \ll c y c l c h g \gg$ and $\ll$ cycldech $\gg$ states (resp. relaxation, charge and discharge mode states) model a regular cycle. This PN could be further folded, transitions and states of the mission profile can be merged. However, for the sake of schema legibility, it is preferable not to merge beyond, the initial state is given by the data $\operatorname{din} 11$ equation described in formula (8), relating to a single cell, when Qomax is equal to $Q^{*}$, Qoal1 is around $Q^{*} . t_{a}$ is the ambient temperature global variable. In the single cell

Fig. 11 Single cell PN

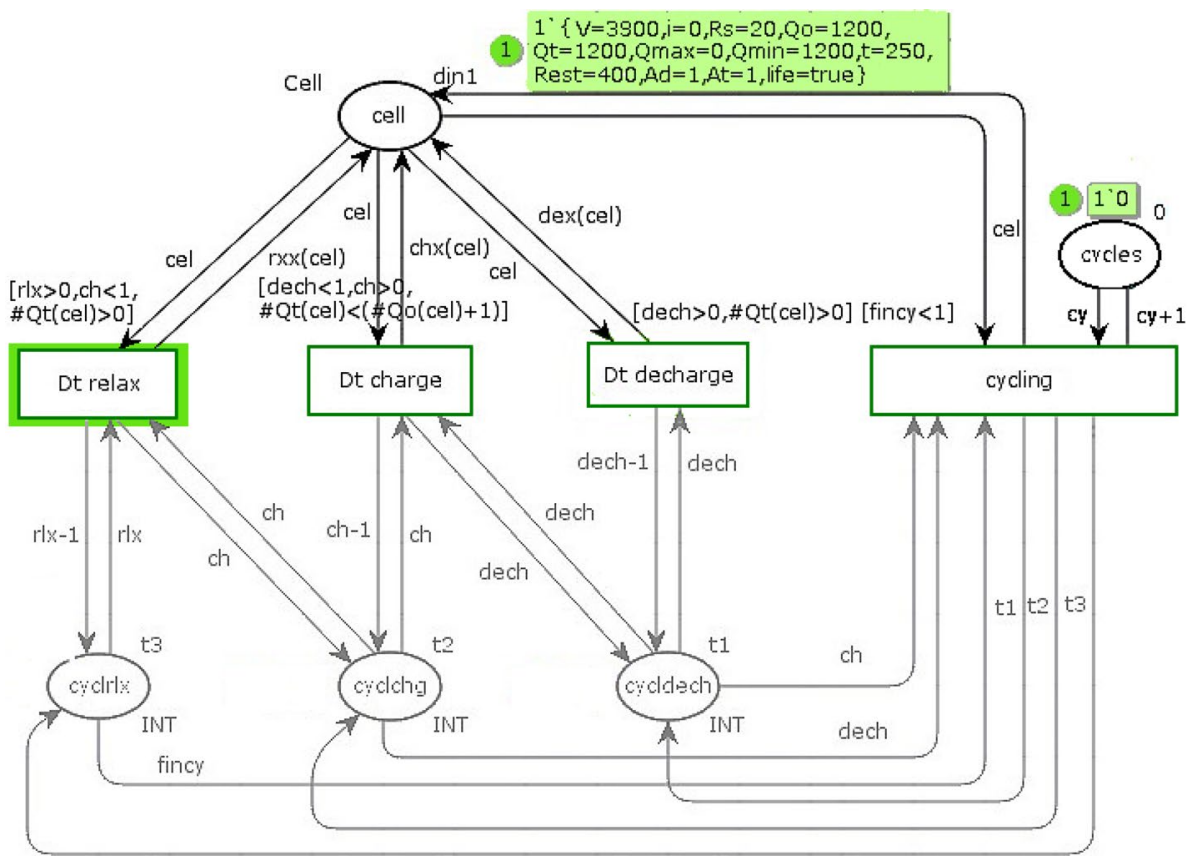


PN, only one switch is modeled. Its ON/OFF state conditions the color « actif $\gg$ (true or false). Other cells can be defined by this way.

$$
\operatorname{din}_{11}=\left\{\begin{array}{c}
n=11, v=3900, i=\text { Qomax div 6, } \\
R s=R s 1, \text { Qo }=\text { Qoal1, Qt = Qoal1 } \\
\text { Qmax }=0, \text { Qmin }=\text { Qoal1 } \\
t=\text { ta }+ \text { discrete }(1,101)-1 \\
\text { Rest }=L f, \text { Ad }=1, \text { At }=1 \\
\text { actif }=\text { true, life }=\text { true }
\end{array}\right\}
$$

To evaluate the cell autonomy (time during which the cell can deliver the electrical charge it has stored when it runs at is nominal current) and lifespan, the cell must be subjected to regular cycling consisting of a discharge phase, during $T 1$, a recharge phase $(T 2)$ and then a relaxation phase 73 , with same duration [50]. An example of $I_{\text {applic }}$ cycling is presented in Fig. 12 for a 1200 mAh cell. The considered cycle allows to discharge two-thirds of the capacity cell under its nominal current [51] for $T 1$. The three states $\ll$ Dtdecharge $\gg, \ll$ Dtcharge $\gg$ and $\ll$ Dtrelax $\gg$ represent the three cycle phases, respectively discharge, charge, relaxation. Each state is connected to a corresponding transition: «cycldec $\gg, \ll c y c l c h g \gg$ and $\ll c y c l r l x \gg$. At any moment, only one transition is firable. When the cycle is complete, the transition $\ll$ cycling $\gg$ increment a counter recording the sudden cycle number, initialized to 0 . The battery output current should be worth $I_{\text {applic }}$ for the mission to be fulfilled. It consists of the sum of internal currents, depending on the architecture.

\section{Battery model}

According to the general electric scheme of an element around a cell (Fig. 1), a battery can respect three ways of manufacturing: a cell parallel-series association (PS), a series-parallel association (SP) or a reconfigurable architecture. One example of a reconfigurable architecture is

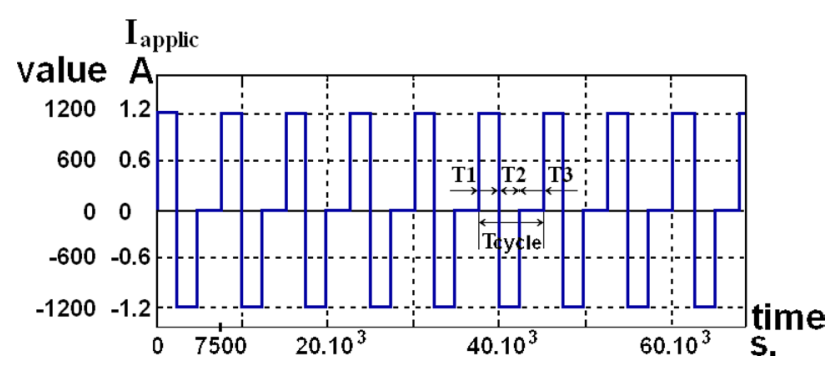

Fig. 12 Cycling mission used in this article: the $\mathrm{C} 3 \mathrm{C}$ architecture (a cell to three cells) [6]. After presenting the battery architectures, these are translate into a PN model.

The most obvious way is to combine $n$ several cells in series by connecting the node $a$ of cell $_{i+1, j}$ to the node $y$ of the cell $_{i, j}$ to let the battery provides output voltage equal to $n . V_{\text {cell }}$. Then this stack of cells can be associated $m$ times in parallel with others, to increase the current to $m$. $_{\text {cell. }}$. This reach the series-parallel (SP) architecture. An example with $n=2$ rows and $m=4$ columns is presented in Fig. 13. A single switch in series is sufficient to isolate or disconnect a column. In consequence, only that of the first row $S_{1 j} A$ has been useful.

By duality, cells can be firstly associated in parallel by connecting all nodes $a$ and all nodes $y$. Then the stacks of cells can be connected in series to increase the voltage. Figure 14 shows an example of parallel-series (PS) architecture with the same structure as in the previous figure. Each cell cell ${ }_{i j}$ must have its switch $S_{i j} A$ to be isolate from the rest of the matrix. Apart from the balancing circuits, these two architectures only need $S_{i j} A$ switches.

Another way to organize the cells inside a battery is to use the $C 3 C$ architecture $[6,52]$, in which each cell of row $i$ and column $j$ is associated by its node $a$ upstream with the three cells from the row $i-1$ and columns $j-1, j$ and $j+1$. Similarly, this cell is associated downstream with the cells of the row $i+1$ and the same three columns by their nodes $b$,



Fig. 13 Series-Parallel (SP) architecture

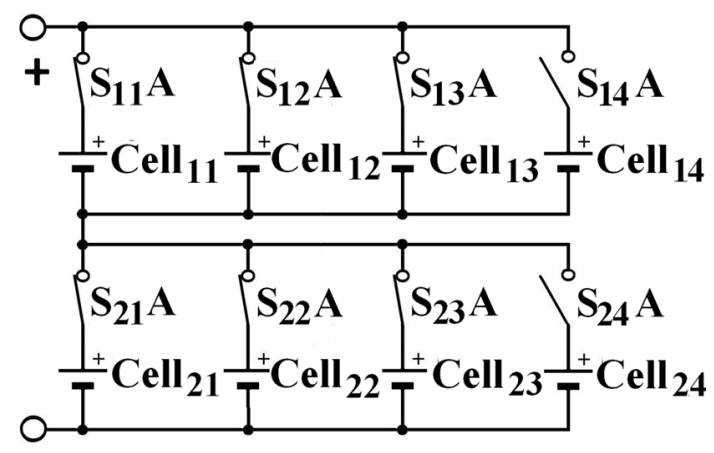

Fig. 14 Parallel-Series (PS) architecture 
$c$ and $d$. An example with the same $(2,4)$ structure as before is shown in Fig. 15. At the Cell ${ }_{i j}$ output, the flow can either be connected directly to the same column cell, or by the switch $S_{i j} B$ on the previous column cell, or by the switch $S_{i j} C$ on the next, respecting the principles described in Fig. 1. The $\mathrm{C} 3 \mathrm{C}$ architecture needs $S_{i j} A, S_{i j} B$ and $S_{i j} C$ switches but no balancing switches.

These three solutions are presented with the last column considered redundant, which also explains the switch attendance in the SP and PS schemes. Having inserted additional cells, which is not practiced in the present industrial solutions, allows degrees of freedom in order to better control cell aging [53]. The switch $S_{i j} Z$ is used only to substitute a short circuit for the $C e l_{i j}$ in a SP architecture and to tolerate this cell failure. In $P S$, only one switch per row $S_{i 1} Z$ is needed in order to substitute the entire row for a short circuit. In C3C, the addition of an $S_{i j} Z$ switch per cell is not necessary because of the large configuration number in the battery [54]. When a cell approaches its failure, it is just as easy to isolate it by using only other cells in the same row and let it in rest. Other solutions exist to ensure internal reconfiguration. This is the case for example in power tree, developed in [55]. Nevertheless, the $\mathrm{C} 3 \mathrm{C}$ solution is the only which can provide its maximum power. In a SP architecture, the redundancy must at least make a column. Also, for homogeneity reasons in this study, in a PS or C3C architecture, a redundant cell will also be added to each row. In that situation, nominal power delivered is given by Eq. (9).

$P_{n}=n \cdot(m-1) \cdot V_{\text {cell }} \cdot I_{\text {cell }}$

A battery is, in the three previous cases, constituted of an ordered list of cells. Thus, it is possible to model a battery from the Fig. 11 scheme, simply by using an ordonned list of token containing all the cells. To identify the tokens, it is then necessary to add a color specifying the number of the cell among the $n * m$ of the battery. A boolean field $\ll$ actif $\gg$ that indicates whether the cell is ON or OFF

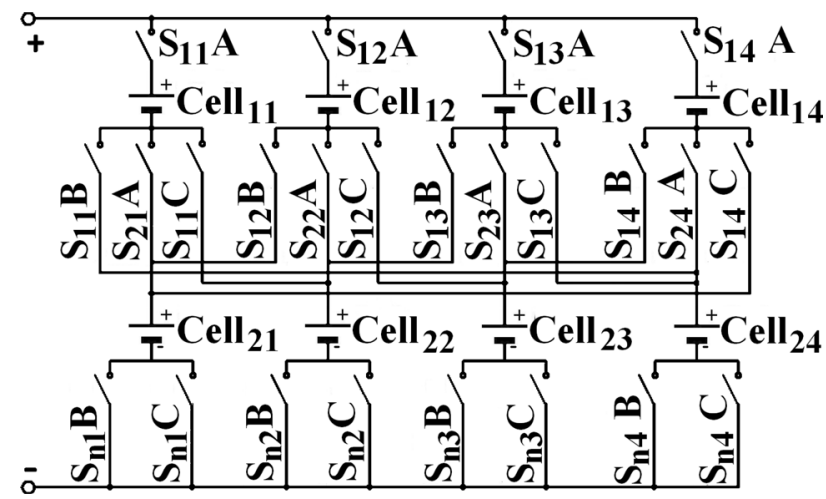

Fig. 15 C3C (a cell to three cells) architecture must be add too. To summarize, a token includes all of the following fields:

$n$ : cell location in the matrix. It is unusual to see batteries of more than ten rows and columns. Beyond that, the batteries consist mainly of associated cell packs, connected together. So just two digits are enough to code the battery topology. For example, $n=23$ for the cell in the third column of the second row. To simulate a single cell, it is sufficient to use one token with $n=11$;

V: OCV, with $3900(\mathrm{mV})$ as initial value for a fully charged lithium-ion cell;

$i$ : current flowing into the cell. Initially, the cell will be considered as entering the discharge phase;

$R s: E S R$, initially having a random value of 20 and $25(m \Omega)$ for a lithium-ion cell;

Qo: the operational charge, worth a random value of \pm 20 (mAh) around mean global variable $Q^{*}=1200 \mathrm{mAh}$;

Qt: instantaneous charge, worth $Q o$ at the beginning;

Qmax: variable used to determine the DoD, initialized to zero at the start and at each cycle change. This value corresponds to the electrical charge for $\mathrm{SoC}=\mathrm{SoC}_{\text {end_of_cycle; }}$

Qmin: another variable measured on a cycle to determine the DoD during the cycle, initialized at Qo and updated with Qmax

$t$ : cell temperature, initialized at room temperature, so at 2500 (in hundredth of Celcius degres) with an initial random between 0 to $+1000\left(c^{\circ} \mathrm{C}\right)$ added;

Rest: RUL, equal at the beginning to $L_{f}$, explains in cycle number;

$A d$ : aging parameter associated with the $\mathrm{DoD}$, equal to 1 at the beginning, calculated at the end of each cycle according to Qmax and Qmin;

At: aging parameter associated with the temperature, initialized to 1;

actif: boolean variable that specifies whether the cell is used (true) or idle, unconnected (false);

life: boolean variable, true if the cell is usable, or false if either Qt or Rest has dropped to 0.

The color is thus associated with the type given by the formula (10):

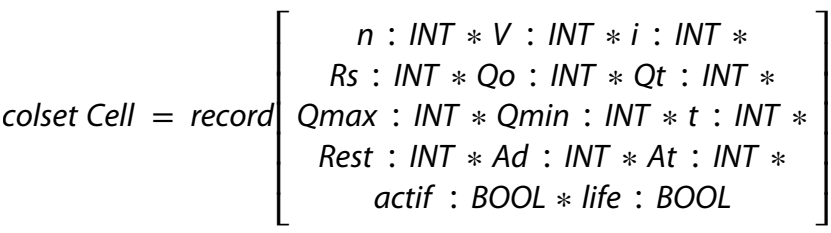

What is more, it is necessary to add the cycling conditions and the various control laws that will make it possible to determine which cells must be active. In a battery, the number of switches is different depending on the architecture. The ON/OFF state of the switch $S_{i j} A$ (Fig. 1 ) always conditions the color actif (true/false). The other switches 
implicitly occur in the functions determining the values of the token integer fields ( $V, I, R s, Q t, Q \max , Q \min )$. We now have a battery PN model whose the values of the different field of the token represent all the modeled aspects of the cells. The PN formalization has advantages, such as the liveliness or the blockage of the system in case of short circuit or cycles in the net. In addition, by using a PN with implicit time, rather than continuous, any punctual defects (imperfections in the current $I_{b a t}$ profile) do not disturb the model operation. On the other hand, by using the same PN for the behavior of the cells and the battery, the computation is carried out globally, on all the data of each cell.

\section{Control laws}

The PN with these control laws is intented to replace the BMS to control the cells. To control the switches, control laws can be established. Some, such as balancing, which uses the + and - switches, are today implemented in industrial solutions. Others, conventional, such as inclusion of additional cells used in redundancy, are not. Still others of an innovative nature, such as activation of the cells according to criteria based on their fundamental states, can be envisaged.

\subsection{Different control laws}

The three control laws studied here are:

- the balancing;

- the redundancy cell management;

- the reconfiguration with an optimization algorithm according to the cell SoH criterion.

Balancing is a technique commonly deployed in batteries, especially in SP architecture. Indeed, because of the disparities that can occur over time between cells on the instantaneous charge, the operational charge and the $E S R$, even if the cells are from the same batch, some will be recharged faster than others. As the BMS monitors the cell SoCs, when it detects excessive imbalance, if battery includes balancing circuits, it can homogenize the charges contained in the cells. To do this, in a SP architecture, it first connects the capacity $C b_{i}$ in parallel to the $C e l l_{a j}$ most charged cell thanks to the $S_{a j}+$ and $S_{a j}$ - switches. Then, it connects this capacity to the least charged Cell ${ }_{b j}$ cell with the $S_{b j}+$ and $S_{b j}-$ switches. This cell to cell technique can improve the charges and consequently improve the battery lifespan [56]. The same principle of balancing is represented between a complete row to another in PS architecture. As already indicated, the $\mathrm{C} 3 \mathrm{C}$ does not include balancing circuits.
The second studied control law is the redundancy management. A battery may comprise more cells than necessary to provide its nominal power, the cells being solicited under their nominal current. As explain before, this nominal current corresponds to this which completely discharges the cell in one hour (SoC falling from 1 to 0 ). To improve the battery reliability in the case of cell failure, cells can be added redundantly. These redundant cells are only used when an initially active cell fails. A cell failure corresponds, in this model, to a cell completely empty $(\mathrm{SoC}=0)$ or too old ( $\mathrm{SoH}=0.8$ or Rest $=0$ ).

Finally, these redundant cells can be used dynamically. For that, the control law have to reconfigure the connections between the cells. Rather than activate them only in the case of a failure, it is possible to use at any time only the cells most able to provide the request current $I_{\text {applic }}$ while reducing their aging and place the others at rest. To do this, it is necessary to define a control law leading to a battery reconfiguration when the active cells less perform than those at rest [5]. SoH is a good indicator to estimate cell aging. These laws behave differently according to the architectures, as mentioned in Table 1. The balancing is usually implemented in SP architectures and is practiced between cells of the same row. It is more rarely deployed in PS and can be practiced between rows. It can be performed between any two cells in C3C. In SP and $C 3 C$, redundancy is realized by one column. It is one cell per row in PS. The SoH-based optimization algorithm must rest the column whose sum of SoH is the lowest, in SP architecture. In PS, the more aged cell (with the weakest $\mathrm{SoH}$ ) of each row is placed at rest. In C3C, the lowest cell in each row must first be idle before defining the best combination between the other cells.

\subsection{Battery complete model}

To simulate options such as using part of the redundant cells and the control laws, it is necessary to add states and transitions to the PN, as well as to define functions.

By principle, when a cell is redundant, it is always initially be the last cell of a row. If redundancy is not actived, the battey operating with the only basic cells, the cell \#life

Table 1 Control law comparison

\begin{tabular}{llll}
\hline & Balancing & Redundancy & SoH-based algorithm \\
\hline SP & Usual & One column & best $\sum_{i=1}^{n} \mathrm{SoH}$ \\
PS & Possible & One cell per row & $\min \left\{\mathrm{SoH}_{j=1}^{m}\right\}_{\text {at rest }}$ \\
C3C & Whatever cell 2 cell & One column & $\min \left\{\mathrm{SoH}_{j=1}^{m}\right\}_{\text {at }}$ \\
& & $\begin{array}{l}\text { rest and best Cells } \\
\text { combination }\end{array}$ \\
& &
\end{tabular}


field is initialized to false. Whether redundancy is enabled or not, the end of mission for a battery is reflected by the presence of two cells of the same row with a \#life data in false.

The PN can be used to simulate a $(n, m)$ battery. In this case, the $\ll$ cell $\gg$ state groups as an ordered list all the tokens each representing one of the cells. Its color is Batt, as specified by the formula (11). The whole strength of the colored PN model is summarized in the fact of being able to synthetically create a multi-colored token list. Each of the colors represents a physical variable. All the colors of the tokens are thus treated at the same time.

Colset Batt = list Cell,

The battery structure is found in the functions that will vary each cell color value and in the initial conditions. In the case of a two rows and four columns structure, the token Bat24 representing this structure is given by the formula (12), with din 11 to din 24 cells have different initial values, in respect with the CPN-Tools spelling.

$$
\text { val Bat24 = } \begin{gathered}
\operatorname{din} 11::\left([\operatorname{din} 12]^{\wedge \wedge}[\operatorname{din} 13]^{\wedge \wedge}[\operatorname{din} 14]^{\wedge \wedge}[\operatorname{din} 21]^{\wedge \wedge}\right. \\
\left.[\operatorname{din} 22]^{\wedge \wedge}[\operatorname{din} 23]^{\wedge \wedge}[\operatorname{din} 24]\right): \text { Batt }
\end{gathered}
$$

The complete scheme simulating the three architectures and all the variants is given in Fig. 16. The light red elements are relative to the balancing management, the parts in dark red to the redundancy and the parts in green to the optimization algorithm. The elements in purple include observers to record, for example, the cell cycle number or their voltage. At the simulation start, the first firable transition is «Dtdecharge $\gg$. To define the used architecture and the control law, it is necessary to initialize the simulation thanks to an initial marking $M_{0}$. Indeed, the initial marking defines the value of the tokens of each state.

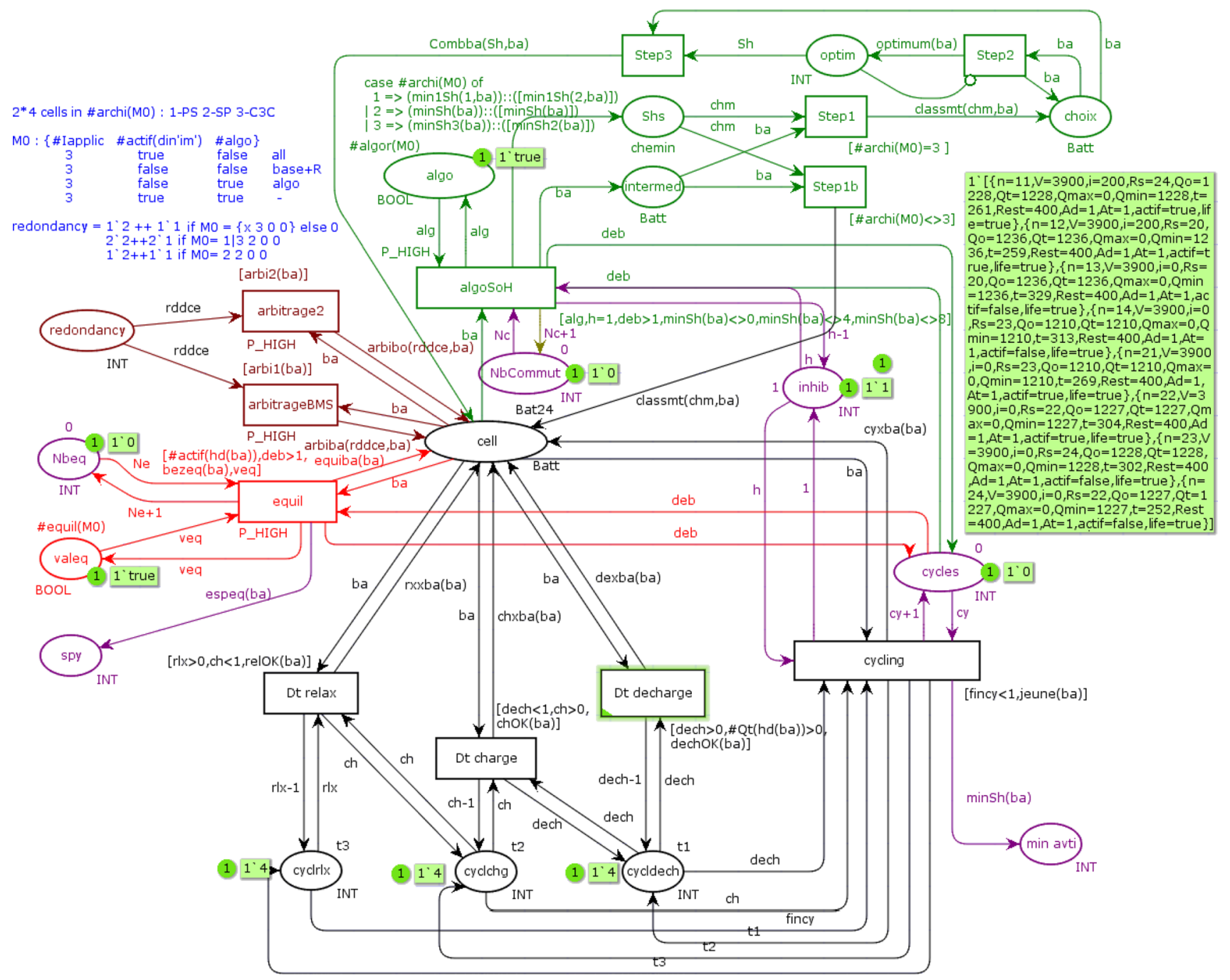

Fig. 16 Complete PN whatever for all the battery architecture 
All meters must be initialized to zero, except $\ll$ inhib $\gg$, initialized to 1 . The three states representing the mission profile are initiated at 4, so as to proceed to a first complete cycling. According to the battery structure and to the control law, a $M_{0}$ function is used to initialize the other states. It is the real initial marking. So, $M_{0}$ is written in the CPN-Tools functions section according to the model of the formula (13). The initial marking of $\ll$ redundancy $\gg$ state is a function of $M_{0}$, explain in blue as a comment in the Fig. 16. The token noted on the right side in the green box is that of the $\ll$ cell $\gg$ state.

$M_{0}=\frac{\{\text { archi }[1 \ldots 3], \text { lapplic }[1 \ldots \text { m }], \text { mactif }[\text { true } / \text { false }],}{\text { algor }[\text { true } / \text { false }], \text { equil }[\text { true } / \text { false }]\}}$

The value 1 for the \#archi data in the \#archi field is associated with a SP architecture, 2 for a PS and 3 for a C3C. The applied current in the discharging and in the charging phases is given by the value of the \#lapplic data. It can vary from once the cell nominal current to $m$ times. When the last column is used, the \#mactif data is true. The \#algor data allows to determine if the optimization algorithm is used or not. It making «algo » state. Thus, a battery operating with a redundant column used in a conventional way have \#mactif at true and \#algo at false. Finally, if the battery includes balancing circuits (between cells of the same column in SP, between the rows in PS, complementary between non-active cells in $(3 \mathrm{C})$, the \#equil data is set to true.

When the state $\ll$ Valeq $\gg$ status token allows balancing (define by \#equil field with an initial marking at true), the bezeq function, in which paseq is the balancing step, examines the cells' $Q t$ levels and use the subfunction level. According to the architecture, if an imbalance appears, the cells are balanced and the Nbeq counter is incremented.

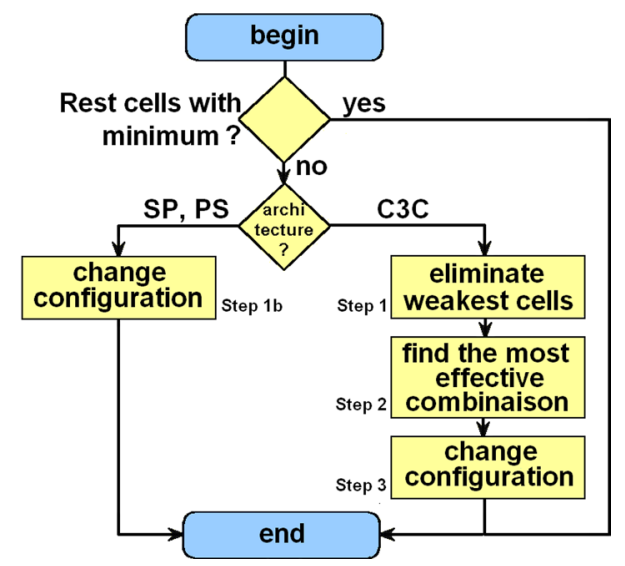

Fig. 17 Rest cells choice algorithm
Since two different reasons can lead to an active cell replacement by the redundant cell: a loss of SoC and a loss of SoH, two different transitions are drawn: $\ll$ arbitrageBMS $\gg$ for a SoH default and $\ll$ arbitrage $2 \gg$ for a SoC default. The part of the network dedicated to the algorithm requires two different schemes depending on whether the architecture is SP, PS or C3C. Indeed, it corresponds to the flowchart given in Fig. 17. If the cells at rest are not the weakest (parameter at minimum) in classical architectures, the configuration is changed (Step 1b). The weakest are put to rest. In C3C, it is first necessary to reduce the possibility universe (Step 1) of all the combinations that comprise the cells placed at rest, before calculating the best combination (Step 2) and change configuration (Step 3) (Tables 2, 3).

To allow an arbitration between the control laws and the mission profile, the associated transitions (《equal $\gg, ~ « a r b i t r a g e B M S \gg, ~ «$ arbitrage $2 \gg$, $\ll$ algoSoH $\gg$ ) have a high priority in front of the others.

\section{Simulations}

A simulation example with this model is presented in this part.

Table 2 Algorithm 1 Bezeq function, to define if the battery need balancing

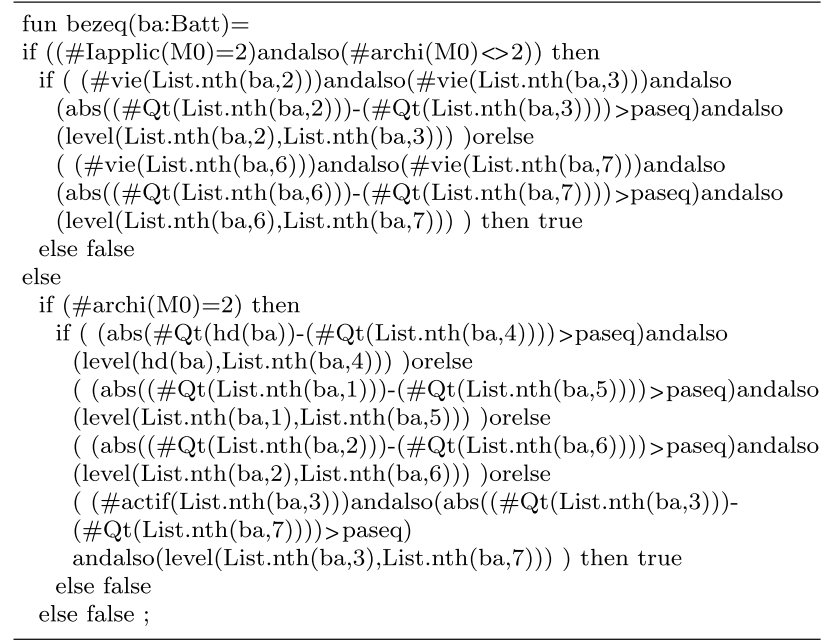

Table 3 Algorithm 2 level function

fun level(c:Cell,d:Cell $)=$

if $(\# \mathrm{Qt}(\mathrm{c}))<(\# \mathrm{Qt}(\mathrm{d}))$ then

if $(\# \mathrm{Qt}(\mathrm{c}))<(\# \mathrm{Qo}(\mathrm{c})$-paseq) then true else false else

if $(\# \mathrm{Qt}(\mathrm{d}))>(\# \mathrm{Qo}(\mathrm{d})$-paseq $)$ then true else false ; 


\subsection{Simulation set}

In this model, a transition is fired in a timed sequence. In CPN-Tools, transitions can be timed. However, the time will be implicitly contained in the passage of certain transitions taking Eq. (14) which recalls the relation between the electric charge $Q$, the current $/$ and the time into account. A $\Delta T$ time implied during a transition firing makes possible to translate a current in an electric charge. Also, the proposed model indirectly considers the time in the transitions. For this modeling, only integer variables are used, to avoid rounding errors during the divisions.

$Q=I . T$,

Cycle time $T_{\text {cycle }}$ (sum of $T 1, T 2$ and $T 3$, resp. charge, discharge and rest times) is fixed at three times $\mathbf{4 0}$ minutes if the cell is requested under its nominal current. Solution deployed in the Fig. 16 PN allows to simulate a phase in four steps. The draw of the three associated transitions thus implies a ten minutes $\Delta T$. For a $Q^{*}=1200 \mathrm{mAh}$ cell, the electric charge variation during $\Delta T$ will be $200 \mathrm{mAh}$. During the first cycle, cell is discharged of $800 \mathrm{mAh}$. The three successive states $\ll$ Dtdecharge $\gg, \ll D$ tcharge $\gg$ and $\ll$ Dtrelax $\gg$ represent the three cycle phases. During one $\Delta T$ time, under the nominal current, the temperature variation under load is set at $+1{ }^{\circ} \mathrm{C}$ in charge and $+6^{\circ} \mathrm{C}$ in discharge. During relaxation, for simplicity, it is considered a linear decrease in temperature of $-7^{\circ} \mathrm{C}$ for this same $\Delta T$ instead of an exponential equilibrium thermodynamic equilibrium time constant.

\subsection{Simulation of a $(2,4)$ battery under different architectures}

The model has been tested under different battery structures. The smaller size of the matrix that compares the architectures requires four columns because in order the $\mathrm{C} 3 \mathrm{C}$ to function normally, three path possibilities must leave from any cell while having an inactive cell in each row. It is also necessary to have at least two rows to ensure balancing.

Simulation starts with new cells whose characteristics are different from a few per cents around their initial capacity and their ESR (\#Qt and \#Rs datas). The «cell $\gg$ state is initialized by the variable Bat24, given by the formula (12) to simulate a $(2,4)$ battery with $n=2$ and $m=4$ structure. A dozen simulations is performed on this network by modifying the initial marking data. By operating the battery under its nominal current $3 . I_{\text {cell, }}$, it is possible to simulate the following variants, for SP and PS: without and with redundancy, with balancing circuits, with redundancy and algorithm optimization; for C3C: with or without active balancing. The parameter chosen to optimize the choice of active cells is $\mathrm{SoH}$. Indeed, in the improving operating dependability perspective, the $\mathrm{SoH}$ appears as the most suitable parameter. The simulation stops when the battery can no longer meet the demand in current. The token representing the battery changes from its initial state, of the type shown in Fig. 16, to its final state. In this one, the number of cells with a \#life data in true is insufficient. Transition fires simulates the charge and the discharge of the cells.

Table 4 shows the simulation results performed with cells having $L_{f}$ equal to 400 cycles. The added $+R$ means that 4 th column cells are used in redundancy. In the Table, the added $+b a l$ says that balancing circuits are activated. The added + algo means that the optimization algorithm is deployed.

These results show that non-balancing conventional architectures have quite similar performances ( 153 cycles for PS, 159 for SP architecture). The battery lifespan is improved with the balancing method, both SP and PS (201 cycles both). Even if in this latter case, the solution is deployed little. On the other hand, the solution with conventional redundancy, namely that the spare cell is connected in place of the first cell to fail (often by aging), improves availability just a little: 160 instead of 153 in PS, 164 instead of 159 in SP. This is because this new cell must provide high currents to supplement the aging of other base cells to which it is connected. This confirms why this improvement is not used in batteries. While in theory it can improve reliability, the complexity of the relationships between cell characteristics means that adding redundant cells does not improve lifespan a lot. Finally, an optimization algorithm use to manage dynamically the redundancy significantly improves the performances (301 cycles for PS, 313 for SP and 320 for C3C architecture). Regardless of the architecture, the lifespan is significantly increased, approximately doubled for this structure. For the $\mathrm{C} 3 \mathrm{C}$ architecture, balancing between idle cells can also help improve the lifespan, extend to 332 cycles instead of 320 . The results obtained with this simplified model, using a PN, are similar to those obtained using a formal model described in Matlab [5], in particular the achievements provided by each control law optimization solution are of the same order.
Table 4 PN simulation results: battery lifespan in cycle numbers

\begin{tabular}{llllllllll}
\hline PS & PS+R & PS+bal & PS+algo & SP & SP+R & SP+bal & SP+aglo & C3C & C3C+bal \\
\hline 153 & 160 & 201 & 301 & 159 & 164 & 201 & 313 & 320 & 332 \\
\hline
\end{tabular}




\subsection{Contribution of the discrete model}

In addition to prove the interest of the balancing method and of the use of an optimization algorithm in the solutions comprising redundant cells, the model allows to classify the different architecture and command combinations according to the quality of the management. At the end of simulation for each architecture, the sum of the lifespan remaining on the critical row is recorded. The critical row has two faulty cells and is responsible for stopping the simulation. With the PS architecture, the sum of the remaining values in the four cell \#Rest fields reaches 255 cycles. In SP architecture, these same cells only contain a total of 55 cycles. In C3C this total is reduced to 42 remaining life cycles. These values are only valid for the presented simulation and are not generic. With other initial conditions, the cells could have aged differently. This value represent no-used time lost in the battery. It nevertheless appears that the $\mathrm{C} 3 \mathrm{C}$ architecture optimizes both the battery aging and the cell agings. Furthermore, to highlighting easily this phenomena by simply read the data contained in the tokens, the discrete model also allows, as expected, to follow in the various fields of tokens the evolution of each cell parameter.

\section{Conclusions}

A battery is a made up of cells and switches. It can thus be modeled by a PN model as any discrete event system to be implanted in the BMS, which integrates the main parameters, such as the temperature, this latter parameter contributing largely to the cell aging. The model proposed here starts from a single cell and is extended to a battery. The PN model is used as a tool to compare different architectures and control laws. The multi-colored token list used allows to treated each color of each token at the same time. It can simulate any type of architecture as well as several control strategies such as redundancy, balancing or resource management according to an optimization algorithm. In the latter case, the model used demonstrates that the cost of adding redundant cells is profitable in terms of lifespan when an optimization algorithm is used to manage the cells to be active. The results obtained on a minimal structure allow to confirm that complexity between cell characteristics means that adding redundant cells does not improve lifespan. It justify the actual choice on balancing. On the other hand, optimizing the activation of the cells in a battery comprising redundant cells, makes it possible to significantly improve the lifespan. The model also highlight the new $\mathrm{C} 3 \mathrm{C}$ solution homogenize the cell agings in a battery. In this way, in a second life use perspective [57, 58], all the cells in the same batteries have a homogeneous $\mathrm{SoH}$, which will simplify the reuse.

\section{Compliance with ethical standards}

Conflict of interest The authors declare that they have no conflict of interest. This study was not specifically funded.

\section{References}

1. International Electrotechnical Commission (2011) Electrical Energy Storage, white paper. IEC, Geneva, Switzerland. ISBN 978-2-88912-889-1

2. Kim H, Shin KG (2012) Dependable, efficient, scalable architecture for management of large-scale batteries. IEEE Trans Ind Inf 8(2):406-417

3. Ota J, Sato T, Akagi H (2016) Enhancement of performance, availability, and flexibility of a battery energy storage system based on a modular multilevel cascaded converter (MMCC-SSBC). IEEE Trans Power Electron 31(4):2791-2799

4. Ci S, Lin N, Wu D (2016) Reconfigurable battery techniques and systems: a survey. IEEE Access 4:1175-1189

5. Savard C, Venet P, Niel E, Pietrac L, Sari A (2018) Comparison of battery architecture dependability. Batteries 4(3):31

6. Savard C, Sari A, Venet P, Niel E, Pietrac L (2016) C3C: a structure for high reliability with minimum redundancy for batteries. In: 17th IEEE international congress of industrial technology, Taipei, Taiwan, pp 281-286

7. Hoque M, Hannan M, Mohamed A (2016) Optimal CC-CV charging of lithium-ion battery for charge equalization controller. In: International Conference on Advances in Electrical, Electronic and Systems Engineering (ICAEES)

8. Khyzhniak T, Kolesnyk V (2013) Modeling of power-supply subsystems of microgrid using Petri nets Electronics and Nanotechnology (ELNANO). In: IEEE 33th international scientific conference

9. Lu D, Fakham DH, Zhou T, Francois B (2010) Application of Petri Nets for the energy management of a photovoltaic based power station including storage units. Renew Energy 35(6):1117-1124

10. Boufaden A, Pietrac L, Gabouj S (2005) L'usage des reseaux de Petri dans la theorie de controle par supervision. Insa Lyon Notes, French

11. Rezvanizaniani S, Liu Z, Chen ZY, Lee J (2014) Review and recent advances in battery health monitoring and prognostics technologies for electric vehicle (EV) safety and mobility. Journal of Power Sources 256:110-124

12. Pelletier $S$, Jabali $O$, Laporte $G$, Veneroni $M$ (2017) Battery degradation and behaviour for electric vehicles: review and numerical analyses of several models. Transp Res Part B Methodol 103:158-187

13. Yoo K, Banerjee S, Kim J, Dutta P (2017) A review of lithium-air battery modeling studies. Energies 10(11):1748

14. Savard C, lakovleva EA (2019) A suggested improvement for small autonomous energy system reliability. Batteries 5:29

15. Smith K, Neubauer J, Wood E, Jun M, Pesaran A (2013) Models for battery reliability and lifetime. Applications in Design and Health Management

16. Smith K, Rahn C, Wang C (2010) Model-based electrochemical estimation and constraint management for pulse operation of lithium ion batteries. IEEE Trans Control Syst Technol 18(3):654663 
17. Berrueta A, Urtasun A, Ursúa A, Sanchis P (2018) A comprehensive model for lithium-ion batteries: from the physical principles to an electrical model. Energy 144:286-300

18. Tippmann S, Walper D, Balboa L, Spier B, Bessler WG (2014) Low-temperature charging of lithium-ion cells part I: electrochemical modeling and experimental investigation of degradation behavior. J Power Sources 252:305-316

19. Dong GZ, Zhang X, Zhang CB, Chen ZH (2015) A method for state of energy estimation of lithium-ion batteries based on neural network model. Energy 90:879-888

20. Wang YJ, Yang D, Zhang X, Chen ZH (2016) Probability based remaining capacity estimation using data-520 driven and neural network model. J Power Sources 315:199-208

21. Wang QK, He YJ, Shen JN, Ma ZF, Zhong ZFGB (2017) A unified modeling framework for lithium-ion batteries: an artificial neural network based thermal coupled equivalent circuit model approach. Energy 138:118-132

22. Khumprom P, Yodo NJE (2019) A data-driven predictive prognostic model for lithium-ion batteries based on a deep learning algorithm. Energies 12(4):660

23. Chan HL (2000) A new battery model for use with battery energy storage systems and electric vehicles power systems. Proceedings of the conference on IEEE power engineering society winter meeting, pp 470-475

24. Urbain M (2009) Modelisation Electrique et Energetique des Accumulateurs Lithium-ion, Estimation en Ligne du SoH. Ph.D. dissertation. Institut National Polytechnique de Lorrain, French

25. Chen KH, Ding ZD (2015) Lithium-ion battery lifespan estimation for hybrid electric vehicle. The 27th Chinese Control and Decision Conference (2015 CCDC), Qingdao, China, pp 5602-5605

26. Yu J (2015) State-of-health monitoring and prediction of lithium-ion battery using probabilistic indication and state-space mode. IEEE Trans Instrum Meas 64:2937-2949

27. Liu X, Qin SH, He Y, Zheng XX, Cao CR (2016) SOC estimation of the lithium-ion battery with the temperature-based Nernst model. In: IEEE 8th international power electronics and motion control conference (IPEMC-ECCE Asia)

28. Lu L, Han X, Li J, Hua J, Ouyang M (2013) A review on the key issues for lithium-ion battery management in electric vehicles. J Power Sources 226:272-288

29. Savoye $F(2012)$ Impact des impulsions periodiques de courant sur la performance et la duree de vie des accumulateurs lithium-ion et consequences de leur mise en oeuvre dans une application transport. Ph.D. dissertation. Universite Claude Bernard-Lyon 1, French

30. Bourlot S, Blanchard P, Robert S (2011) Investigation of aging mechanisms of high power $\mathrm{Li}$-ion cells used for hybrid electric vehicles. J Power Sources 196:6841-6846

31. Mahalakshmi S, Datchanamoorthy S (2015) Prediction of wireless sensor battery life. IEEE Autotestcon, National Harbor, MD, pp 138-145

32. Riviere E, Venet P, Sari A, Meniere F, Bultel Y (2015) LiFePO4 battery state of health online estimation using electric vehicle embedded incremental capacity analysis. IEEE vehicle power and propulsion conference (VPPC). Montreal, QC, p 2015

33. Wang J, Liu P, Hicks-Garner J, Sherman E, Soukiazian S, Verbrugge M, Tataria H, Musser J, Finamore P (2010) Cycle-life model for graphite-LiFePO4 cells. J Power Sources 196:3942-3948

34. Soussens M, Laulheret R, Cabardaye A (2014) Modeles de degradation des batteries d'accumulateurs. CNES Notive, French

35. Okubo M, Tanaka Y, Zhou H, Kudi T, Honma I (2009) Determination of activation energy for $\mathrm{Li}$-lon diffusion in electrodes. J Phys Chem 113:2840-2847

36. Lievre A, Sari A, Venet $P$, Hijazi A, Ouattara-Brigaudet $M$, Pelissier S (2016) Practical online estimation of lithium-ion battery apparent series resistance for mild hybrid vehicles. IEEE Trans Veh Technol 65:4505-4511

37. Damay N, Friedrich G, Forgez C (2016) Modelisation thermique en vue du dimensionnement d'un pack batterie, avec prise en compte du couplage electro-thermique pour la caracterisation des pertes electriques. Symposium de Genie Electrique, French. Grenoble, France

38. Mahbubul IM, Khan MMA, Ibrahim NI, Ali HM, Saidur R (2018) Carbon nanotube nanofluid in enhancing the efficiency of evacuated tube solar collector. Renew Energy 121:36-44

39. Al-Waeli AHA, Sopian K, Chaichan MT, Kazem HA, Hasan HA, Al-Shamani AN (2017) An experimental investigation of SiC nanofluid as a base-fluid for a photovoltaic thermal PV/T system Author links open overlay panel. Energy Convers Manag 142:547-558

40. Ali M, Khan SA, Sheikh NA, Gilani SI, Rashid TU (2017) Performance analysis of a low capacity solar tower water heating system in climate of Pakistan. Energy Build 143:84-99

41. Hijazi A (2010) Modelisation electrothermique, commande et dimensionnement d'un systeme de stockage d'energie par supercondensateurs avec prise en compte de son vieillissement: application la recuperation de l'energie de freinage d'un trolleybus. Ph.D. thesis. Universit Claude Bernard - Lyon 1, French

42. Damay N (2013) Modelisation thermique d'une batterie Li-ion prismatique de grande capacite et validation experimentale. JCGE 2013 Conference, France

43. Giegerich $M$, Koffel $S$, Filimon R, Grosch J, Fhner T, Wenger $M$, Gepp M, Lorentz V (2013) Electrothermal modeling and characterization of high capacity lithium-ion battery systems for mobile and stationary applications. IECON 2013-39th annual conference of the IEEE industrial electronics society, Vienna, pp 6721-6727

44. Shin D, Poncino M, Macii E (2014) Thermal management of batteries using a hybrid supercapacitor architecture. Design, Automation and Test in Europe Conference and Exhibition, Dresden

45. Jaguemont J, Dube $Y$, Bouton $L$ (2016) Characterization and modeling of a hybrid-electric-vehicle lithium-ion battery pack at low temperatures. IEEE Trans Veh Technol 65:1-14

46. DeMar P (2012) Thermal runaway-How to halt it and recover from it and How to detect it and prevent it. Intelec 2012, Scottsdale, AZ

47. Faerdella R, Barruet C, Grenouilloux C (2016) Cyclage en temprature des profils complexes FIDES. 20me Congrs de matrise des risques et de sret de fonctionnement, Saint Malo, French

48. Ali HM, Arshad W (2017) Effect of channel angle of pin-fin heat sink on heat transfer performance using water based graphene nanoplatelets nanofluids. Int J Heat Mass Transf 106:465-472

49. Abdelhedi R, Ammari A, Lahyani A, Venet $P$ (2016) Optimal power sharing between batteries and supercapacitors in electric vehicles. In: 7th International conference on sciences of electronics, technologies of information and telecommunication (SETIT)

50. Sato K, Yachi T, Takeuchi A, Babasak T (2011) Battery management for fuel cell/battery hybrid power supply system. In: IEEE 33rd international telecommunications energy conference (INTELEC), Amsterdam, Netyherlands

51. Omar N, Daowd M, Hegazy O, Mulder G, Timmermans JM, Coosemans T, Van den Bossche P, Van Mierlo J (2012) Standardization work for BEV and HEV applications: critical appraisal of recent traction battery documents. Energies 5:138-156

52. Savard C, Venet P, Pietrac L, Niel E, Sari A (2018) Increase lifespan with a cell management algorithm in electric energy storage systems. In: 19th International conference on industrial technology. Lyon, France, pp 1748-1753

53. Savard C, Niel E, Venet P, Pietrac L, Sari A (2017) Modelisation par un graphe de flots d'une architecture alternative pour les 
systemes de stockage multi-cellulaire de l'energie electrique. SEEDS Days-JCGE 2017, French. Arras, France

54. Savard C (2017) Amelioration de la disponibilite operationnelle des systemes de stockage de l'energie electrique multicellulaires. Ph.D. dissertation. Universite de Lyon, INSA de Lyon. French

55. Jin F, Shin K (2012) Pack sizing and reconfiguration for management of large-scale batteries cyber-physical systems (ICCPS). IEEE/ACM Third International Conference. Beijing, China, pp 138-147

56. Beirao M, do Rosario-Calado M, Pombo J, Mariano S (2016) Balancing management system for improving Li-ion batteries capacity usage and lifespan. IEEE 16th international conference on environment and electrical engineering (EEEIC)
57. Martinez-Laserna E, Sarasketa-Zabala E, Villareall I (2018) Technical viability of battery second life: a study from the ageing perspective. IEEE Trans Ind Appl 54:2703-2713

58. Quinard H, Redondo-Iglesias E, Pelissier S, Venet P (2019) Fast electrical characterizations of high-energy second life lithiumion batteries for embedded and stationary applications. Batteries 5:33

Publisher's Note Springer Nature remains neutral with regard to jurisdictional claims in published maps and institutional affiliations. 